\title{
Tensile behaviors of highly flowable strain hardening fiber reinforced concrete
}

\author{
W. C. Liao \\ Department of Civil Engineering, National Taiwan University, Taiwan
}

\begin{abstract}
Highly flowable strain hardening fiber reinforced concrete (HF-SHFRC) combines the excellent workability of self-consolidating concrete (SCC) in the fresh state, with the strain-hardening and multiple cracking characteristics of high performance fiber reinforced cementitious composites (HPFRCC) in their hardened state. This paper presents six HF-SHFRC mix designs, with compressive strengths ranging from 35 to $66 \mathrm{MPa}$. The results of two tensile tests, direct tensile test (dog-bone shaped specimen) and long prismatic tensile test with continuous reinforcement, are also carried out in this paper. All the mixtures show quite satisfactory in flowability and tensile properties, including strain-hardening and enhanced strain capacity due to the presence of the reinforcing steel strand.

Keywords: strain hardening, SCC, HPFRCC, multiple cracking.
\end{abstract}

\section{Introduction}

Highly flowable strain hardening fiber reinforced concrete (HF-SHFRC) combine the self-consolidating property of self-consolidating concrete (SCC) in their fresh state, with the strain-hardening and multiple cracking characteristics of high performance fiber reinforced cement composites (HPFRCC) in their hardened state. SCC has a high flowability and a moderate viscosity, and has no blocking by the reinforcement during flow. With proper use of superplasticizer (SP) and viscosity modifying agents (VMA), SCC can achieve higher flowability and higher slump without segregation, and also maintain better slump retention, thus making concrete more durable due to its lower water/cementitious ratio, and reducing sulfate attack and salt penetration. 
Not only the fresh state characteristics of SCC, HF-SHFRC also has excellent mechanical properties as HPFRCC. HPRCC has the tensile strain-hardening response with multiple cracking exhibits instead of the tensile strain-softening response observed in conventional fiber reinforced concrete (FRC) as shown in Fig. 1 (Naaman $[1,2]$ ).

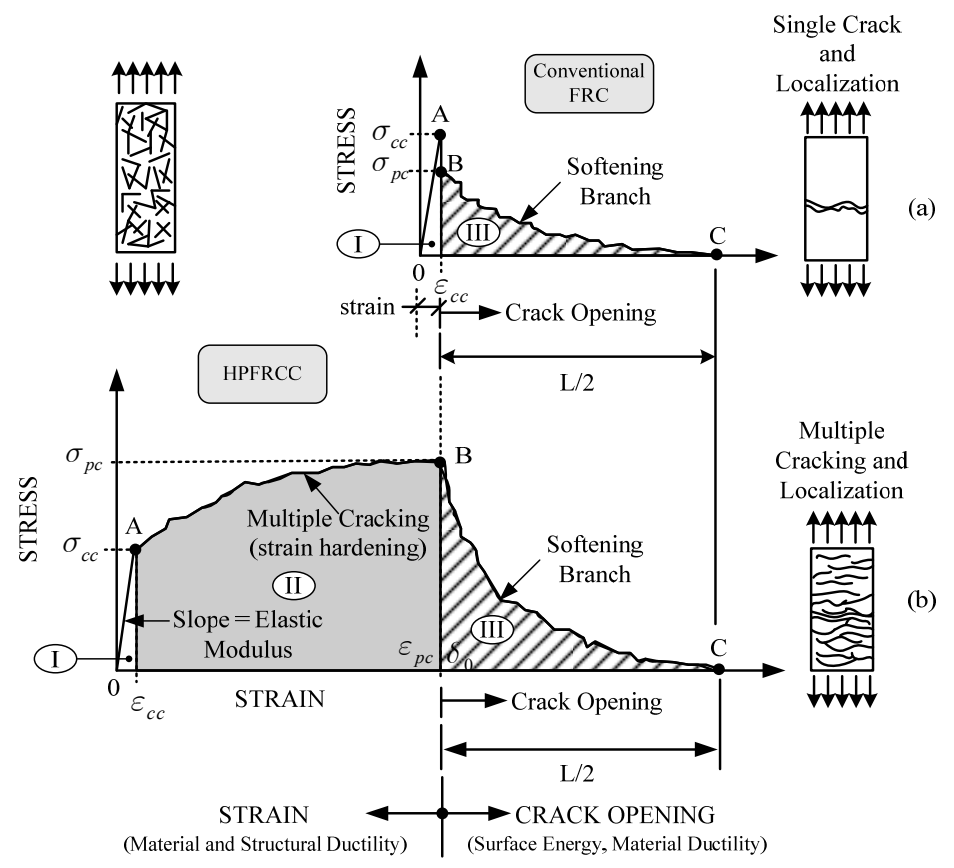

Figure 1: Tensile stress-strain response of conventional FRCC and HPFRCC.

Series of HF-SHFRC for different compressive strength demands (35 to $66 \mathrm{MPa}$ ) have been successfully developed by Liao et al. [3, 4] by modifying SCC mixtures recommended in previous studies and using the available local materials, including $30 \mathrm{~mm}$ long steel hooked fibers in volume fractions of $1.5 \%$ and $2 \%$.

Two tensile tests, direct tensile test (dog-bone shaped specimen) and long prismatic tensile test with continuous reinforcement, are also carried out to verify all the HF-SHFRC mixtures. The former one is the best way to determine the fundamental tensile behavior of HPFRCC. The latter one can further account for more realistic fiber distribution and incorporation of the stiffening effect due to continuous reinforcement. 


\section{Mix design}

\subsection{Materials}

Based on an extensive review of prior studies on SCC mixtures with fibers, six mixtures of HF-SHFRC (initially taken from prior studies and modified), were developed are described next. The cementitious materials used in this study were ASTM Type III Portland cement and class C fly ash. The coarse aggregate had a maximum size of $12.7 \mathrm{~mm}$ and consisted of either solid crushed limestone or pea gravel from a local source, with a density of about $2.70 \mathrm{~g} / \mathrm{cm} 3$. The fine aggregate was \#16 flint silica sand (ASTM 50-70). Two polycarboxylate-based superplasticizers (SP1 and SP2) were used in various mixtures. In addition to the superplasticizer, a viscosity modifying admixture (VMA) was used in some mixtures to enhance the viscosity and reduce fiber segregation in the presence of higher water to cementitious ratios. Two types of hooked steel fiber with circular cross-section were used, one with normal tensile strength and one with higher tensile strength and higher aspect ratio. Their main properties are shown in Table 1 .

Table 1: $\quad$ Properties of steel hooked fibers.

\begin{tabular}{|c|c|c|c|c|c|c|}
\hline $\begin{array}{c}\text { Fiber } \\
\text { ID }\end{array}$ & Type & $\begin{array}{c}\text { Diameter, } \\
(\mathrm{mm})\end{array}$ & $\begin{array}{c}\text { Length, } \\
(\mathrm{mm})\end{array}$ & $\begin{array}{c}\text { Aspect } \\
\text { ratio }\end{array}$ & $\begin{array}{c}\text { Tensile } \\
\text { Strength, } \\
(\mathrm{MPa})\end{array}$ & $\begin{array}{c}\text { Elastic } \\
\text { Modulus, } \\
(\mathrm{GPa})\end{array}$ \\
\hline SF 1 & Hooked & 0.38 & 30 & 79 & 2300 & 200 \\
\hline SF 2 & Hooked & 0.55 & 30 & 55 & 1100 & 200 \\
\hline
\end{tabular}

\subsection{Mix proportions}

Six different HF-SHFRC mixtures were developed to cover a broad range of strength requirements. Mixture $\mathrm{C} 1$ was essentially taken, as a starting reference point, from Bui et al. [5]. The mix proportions recommended, after several preliminary trials for each mixture, are summarized in Table 2. In this study, the amount of superplasticizer (SP) and the ratio of water-to-cementitious materials were selected as primary means to modify the compressive strengths.

In addition, the fiber volume fraction for all mixtures was larger than or equal to $1.5 \%$. It is noted that all these proportions were developed based on the following philosophy, that is, to reduce the coarse-to-fine aggregate ratio in order to provide a well-developed paste layer which can fully surround individual coarse aggregates. This is because the amount of paste must be sufficient not only to fill the voids between aggregates, but also to fully cover the aggregate particles and the fibers. 
Table 2: $\quad$ Proportions of HF-SHFRC mixtures $\left(\mathrm{kg} / \mathrm{m}^{3}\right)$.

\begin{tabular}{|c|c|c|c|c|c|c|c|}
\hline \multicolumn{2}{|c|}{ Series ID } & $\mathrm{C} 1$ & $\mathrm{C} 2$ & C3 & $\mathrm{C} 4$ & $\mathrm{C} 5$ & C6 \\
\hline Cement & Type III & 472.3 & 465.8 & 474.0 & 350.6 & 409.9 & 373.1 \\
\hline $\begin{array}{c}\text { Mineral } \\
\text { Admixture }\end{array}$ & Fly Ash & 226.7 & 232.9 & 237.0 & 306.8 & 274.6 & 326.4 \\
\hline $\begin{array}{c}\text { Fine } \\
\text { Aggregates }\end{array}$ & $\begin{array}{c}\text { Silica Sand } \\
\quad \# 16\end{array}$ & 802.8 & 791.9 & 805.8 & 876.5 & 860.8 & 820.8 \\
\hline \multirow{2}{*}{$\begin{array}{c}\text { Coarse } \\
\text { Aggregates }\end{array}$} & $\begin{array}{c}\text { Crushed } \\
\text { Limestone }\end{array}$ & 519.5 & 465.8 & 474.0 & 438.2 & & 447.7 \\
\hline & Pea gravel & & & & & 450.9 & \\
\hline Water & Water & 212.5 & 279.5 & 284.4 & 294.5 & 274.6 & 298.5 \\
\hline \multirow{3}{*}{$\begin{array}{l}\text { Chemical } \\
\text { Admixture }\end{array}$} & SP 1 & 12.8 & 7.0 & 4.7 & & 5.3 & \\
\hline & SP 2 & & & & 1.9 & & 1.9 \\
\hline & VMA & & 5.6 & 4.5 & 22.8 & 5.3 & 14.2 \\
\hline \multirow{2}{*}{ Steel Fiber } & SF 1 & & 151.4 & 115.7 & 108.7 & 118.5 & 117.5 \\
\hline & SF 2 & 153.5 & & & & & \\
\hline \multicolumn{2}{|c|}{ Total Weight } & 2400 & 2400 & 2400 & 2400 & 2400 & 2400 \\
\hline \multicolumn{2}{|c|}{$V_{f}(\%)$} & 1.96 & 1.92 & 1.50 & 1.50 & 1.50 & 1.50 \\
\hline
\end{tabular}

\section{Experimental program}

\subsection{Slump flow test}

The slump flow test on the fresh mixture, and compression and direct tensile tests on the hardened composite were carried out to estimate flowability, compressive strength, and tensile response, respectively. The slump flow test was the easiest and most familiar way to evaluate the horizontal free flow (deformability) of SCC in the absence of obstructions. The diameter of the spread concrete is measured in two perpendicular directions and recorded as slump flow. In general, the average of diameters in two perpendicular directions should be larger than $600 \mathrm{~mm}$ for qualified SCC.

\subsection{Compression test}

The compressive strength of hardened concrete was determined from compression tests on standard cylindrical specimens $100 \times 200 \mathrm{~mm}$ according to ASTM C39 (ASTM 2005).

\subsection{Direct tensile test}

The direct tensile tests were needed to ascertain that the developed HF-SHFRC give a strain-hardening response in tension after first cracking. Dog-bone shaped tensile specimens were prepared and tested for each HF-SHFRC mixture (Naaman [2]). These specimens have a cross-sectional dimension of $25.4 \times$ 
$50.8 \mathrm{~mm}$ as shown in Figure 2(a). The applied load was monitored by the load cell of the testing machine and the elongation was recorded by a pair of linear variable differential transformers (LVDT) attached to the specimen (Figure 2(b)), with a gauge length of about $178 \mathrm{~mm}$. It is noted that compared to the fiber length, the relatively smaller cross section may lead to a somewhat twodimensional distribution of fibers.
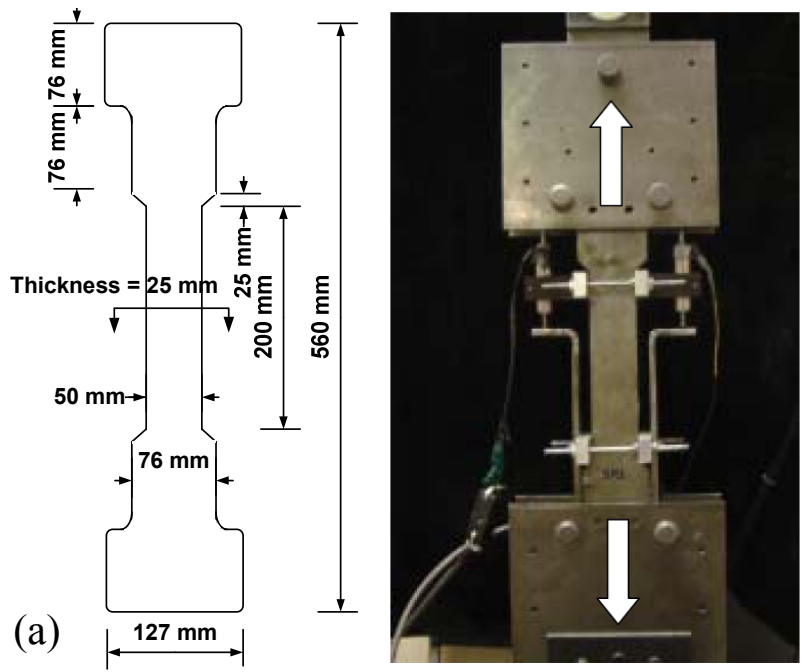

Figure 2: (a) Geometry and dimensions of tensile test (dog-bone) specimen;

(b) tensile test set-up.

\subsection{Long prismatic reinforced tensile test}

It has been established that the presence of continuous reinforcement helps concrete to carry tension between cracks through transfer of bond forces. This in turn results in better control on member stiffness, deformation, and crack widths in RC members as compared to plain concrete members. In this study, an unstressed prestressing steel strand was placed at the centroid of the specimen to simulate the presence of reinforcing steel in HF-SHFRC by Chao et al. [6]. The advantage of using a prestressing steel tendon is that a strain as high as $0.9 \%$ can be applied while the tendon remains linear elastic, thus allowing a stable environment for loading-unloading and for measurements of crack width and spacing at every loading step. Moreover, tests conducted by Chao et al. [7] have shown that HPFRC composites lead to a much higher bond strength between a seven-wire strand and surrounding matrix than plain concrete (as high as three times), thus ensuring the tension stiffening effect in the test specimens.

Details of the specimen geometry, test setup, and instrumentation are shown in Figure 3. The long prismatic specimen has a cross-sectional dimension of $64 \times 76 \mathrm{~mm}$. The specimen was placed in a prestressing bed and supported by a few steel strips which allowed the specimen to move easily on its bed support 
during tension. The strand going through the specimen was attached at each end by a prestressing chuck. The tensile load was applied monotonically to the strand through a hydraulic jack and recorded by a pair of load cells at both ends of the prestressing bed as shown in Figure 3(a). Five zones in the middle of the specimen were selected to record the strains in the concrete through the use of LVDTs, as shown in Figure 3(b) (Zones 1 thru 5). The gauge length of each zone was $250 \mathrm{~mm}$. Elongation of the entire specimen was also monitored by two LVDTs attached to the ends of the specimen. Strains in the strand (inside the matrix) were measured by strain gauges attached at pre-designated locations corresponding to the middle points of the five zones (Zones 1 thru 5) mentioned above. Strain gauges were also mounted on the strand outside the matrix (Figure $3 b)$ in order to obtain the stress-strain curve of the bare strand.

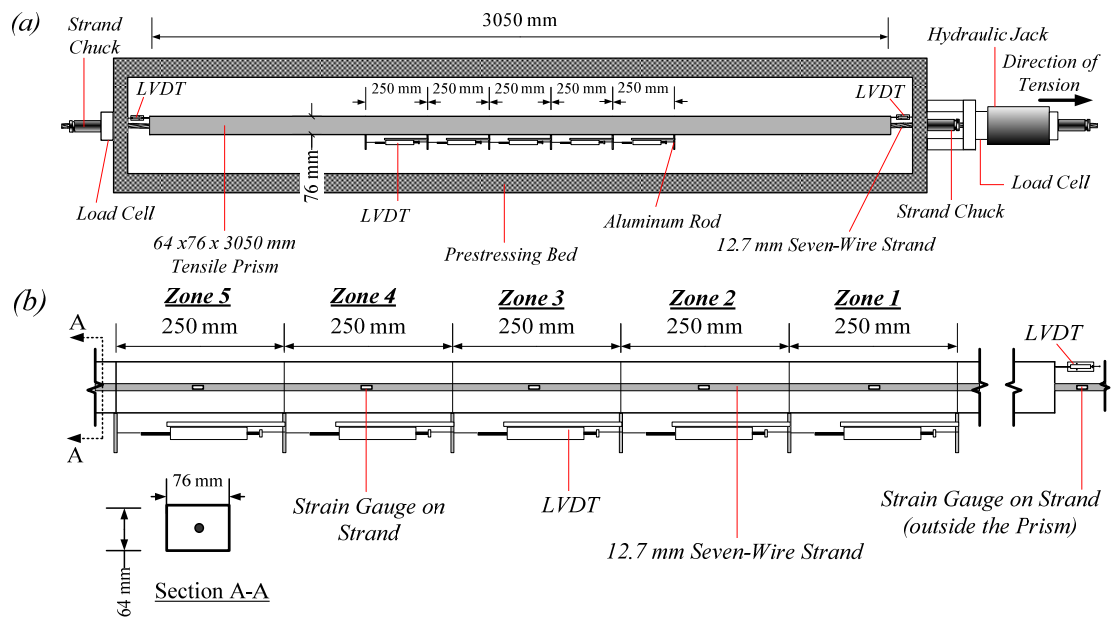

Figure 3: (a) Geometry and dimensions of tensile test (dog-bone) specimen; (b) tensile test set-up.

The stress in the fiber concrete for the long prismatic reinforced tensile test was calculated by:

$$
\sigma_{c}=\left(F-E_{s} \varepsilon_{s}\right) /\left(A_{t}-A_{s}\right)
$$

where $\sigma_{c}$ is the tensile stress in fiber concrete $(\mathrm{MPa}) ; F$ is the total force measured by load cell $(\mathrm{kN}) ; E_{s}$ is the elastic modulus of strand $(\mathrm{MPa}) ; \varepsilon_{s}$ is the strain in strand measured by strain gauge $(\mathrm{mm} / \mathrm{mm}) ; A_{c}$ is the gross crosssectional area of the specimen $\left(=4860 \mathrm{~mm}^{2}\right) ; A_{s}$ is the nominal cross-sectional area of a $12.7 \mathrm{~mm}$ seven-wire strand $\left(=100 \mathrm{~mm}^{2}\right)$. It was mentioned previously that a prestressing steel strand remains linear elastic when the strain reaches as high as $0.9 \%$. This was indeed the case in the strand used in this study, as indicated by the stress-strain relation obtained based on strain gauges mounted outside the matrix; the curve was linear with an elastic modulus of $206 \mathrm{GPa}$. Since the specimen was able to move freely during testing with minor frictional force, the force measured by the load cell $(F)$ can be taken as constant along the 
specimen and used for Zones 1 thru 5. The force sustained by the fiber concrete was calculated by the difference between $F$ and force in the strand $E_{s} \varepsilon_{s}$. The average tensile stress was then calculated by dividing the force difference using the net concrete area $A_{c}-A_{s}$. The tensile strains in the fiber concrete were obtained by dividing the elongation (measured through LVDTs) by the gauge length of each zone $(=250 \mathrm{~mm})$. It is also noted that only mixture C3 was used in this long prismatic reinforced tensile test

\section{Experimental results}

\subsection{Slump flow test}

As described earlier, slump flow of HF-SHFRC can be recorded as the average diameter of the concrete in two perpendicular directions. It was measured for each mixture. Flow diameters about $600 \mathrm{~mm}$ were achieved in most cases and its value is shown in Table 3.

Table 3: Slump flow, compression test and direct tensile test results of HFSHFRC.

\begin{tabular}{|c|c|c|c|c|c|c|c|}
\hline \multicolumn{2}{|c|}{ Series ID } & $\mathrm{C} 1$ & $\mathrm{C} 2$ & $\mathrm{C} 3$ & $\mathrm{C} 4$ & $\mathrm{C} 5$ & C6 \\
\hline \multicolumn{2}{|c|}{$V_{f}(\%)$} & 1.96 & 1.92 & 1.50 & 1.50 & 1.50 & 1.50 \\
\hline Slump & Slump flow & 565 & 518 & 603 & 582 & 613 & 579 \\
\hline flow test & $(\mathrm{mm})$ & 578 & 525 & 601 & 568 & 602 & 552 \\
\hline $\begin{array}{c}\text { Compression } \\
\text { test }\end{array}$ & $\begin{array}{c}\left(f_{c}^{\prime}\right) \\
\text { 28-day }(\mathrm{MPa})\end{array}$ & 65 & 67.9 & 65 & 36.4 & 43.6 & 39.3 \\
\hline \multirow{5}{*}{$\begin{array}{c}\text { Direct tensile } \\
\text { test }\end{array}$} & $\begin{array}{l}\text { Average Post- } \\
\text { Cracking } \\
\text { Strength }(\mathrm{MPa})\end{array}$ & N/A & 6.57 & 5.41 & 3.59 & 4.64 & 3.61 \\
\hline & $\begin{array}{l}\text { Average Strain at } \\
\text { Peak Stress }(\%)\end{array}$ & $\mathrm{N} / \mathrm{A}$ & 0.25 & 0.34 & 0.25 & 0.39 & 0.45 \\
\hline & $\begin{array}{l}\text { Stress at apparent } \\
\text { strain }=0.5 \% \\
\text { (\% of peak } \\
\text { stress) }\end{array}$ & N/A & $\begin{array}{l}5.80 \\
(88)\end{array}$ & $\begin{array}{l}4.85 \\
(90)\end{array}$ & $\begin{array}{l}2.99 \\
(83)\end{array}$ & $\begin{array}{l}3.86 \\
(83)\end{array}$ & $\begin{array}{l}3.54 \\
(98)\end{array}$ \\
\hline & $\begin{array}{c}\text { Average Number } \\
\text { of Cracks }\end{array}$ & N/A & 5 & 9 & 6 & 9 & 6 \\
\hline & $\begin{array}{l}\text { Average Crack } \\
\text { Spacing }(\mathrm{mm})\end{array}$ & N/A & 29.7 & 18.0 & 25.7 & 18.0 & 25.7 \\
\hline
\end{tabular}

\subsection{Compression test}

The average compressive strength of each HF-SHFRC mixture is also given in Table 3. Figure 4 shows typical stress-strain curves in compression of the HFSHFRC mixtures. It can be observed that all HF-SHFRC behave as wellconfined reinforced concrete in compression. 


\subsection{Direct tensile test}

In terms of tensile tests, the stress-strain curves were recorded from the dog-bone specimens tested. Multiple cracks developed up to peak stress (post-cracking strength) at which crack localization occurred as shown in Fig 5. Typical stressstrain curves are shown in Figure 4. It can be observed that the tensile stress increases with an increase in strain after the first crack. Thus these mixtures all satisfy the requirement of strain-hardening behavior of HPFRCC. Beyond the peak stress, the tensile stress dropped gradually due to fiber kinematic pullout from the matrix. Some key results are summarized in Table 3.
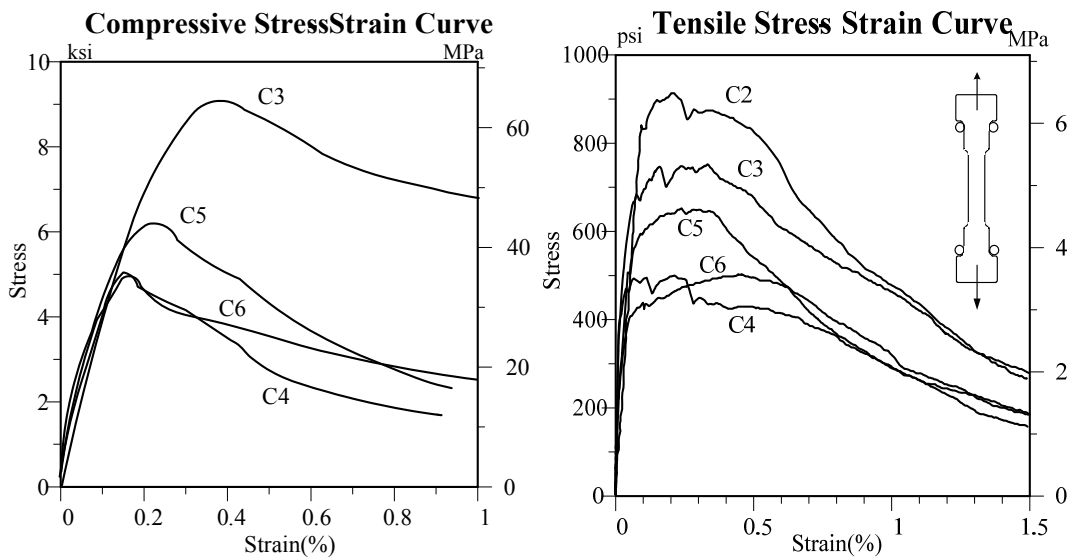

Figure 4: Typical compressive and tensile stress-strain curves of HF-SHFRC.
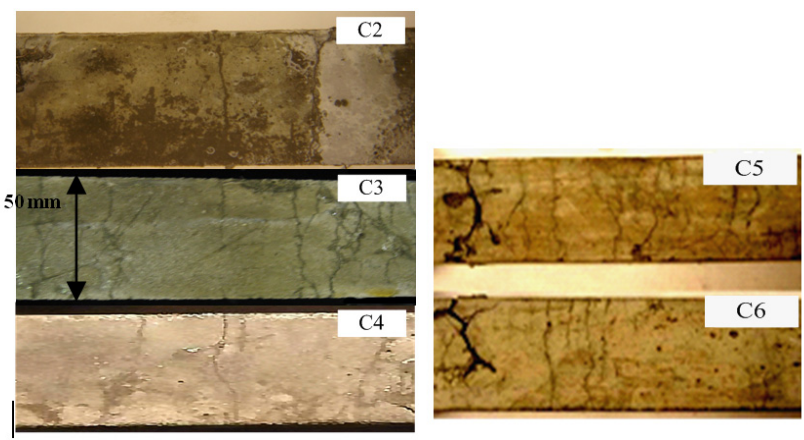

Figure 5: Typical multiple cracks observed in HF-SHFRC specimens.

\subsection{Long prismatic reinforced tensile test}

Typical tensile load-elongation responses of the composite and bare strand in Zone 3 are shown in Figure 6(a). Stress-strain response of the HF-SHFRC C3 mixture was also obtained based on the equation mentioned in section 3.4 and 
plotted in Figure 6(b), along with an envelope curve. The unloading loops were the result of softening of the hydraulic jack during crack measurement and photographing.
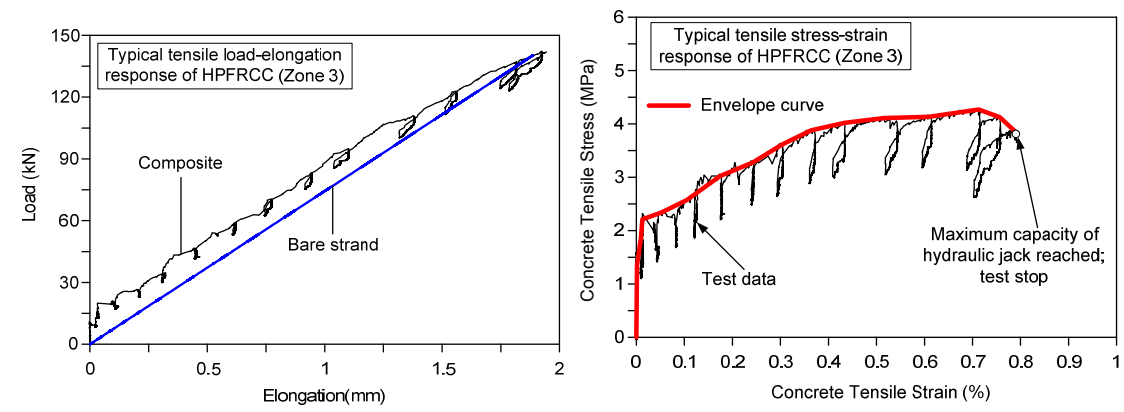

Figure 6: Typical tensile (a) load-elongation and (b) stress-strain responses of HF-SHFRC.

Figure 6(b) shows that the HF-SHFRC used in this study exhibited tensile strain-hardening behavior up to $0.7 \%$ composite strain, along with extensive multiple cracking as shown in Figure 8. The stress-strain curve is generally very stable without any sudden degradation in strength. This can be attributed to the presence of the longitudinal reinforcement, which was able to redistribute tensile stress through bond when cracks occurred. Moreover, compared the crack distributions in the direct tensile test (Figure 4) and long prismatic reinforced tensile test (Figure 7) specimens, more extensive multiple cracks and no significant damage localization can be observed in the long prismatic reinforced one.

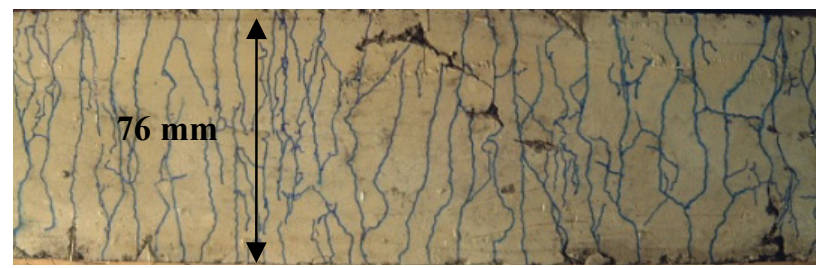

Figure 7: Crack distributions in long prismatic reinforced tensile test.

Figure 8 compares the tensile stress-strain responses of the direct tensile test and long prismatic reinforced tensile test specimens made of the same HFSHFRC mixture. It is observed that the peak tensile strength of the former one is higher than that of the long prismatic reinforced specimen. This can be attributed to scale effects and to the possible two-dimensional versus three-dimensional fiber orientations in each specimen, respectively. In addition, the onset of damage localization as a result of fiber pullout at peak stress is significantly delayed in the presence of continuous reinforcement. Indeed, the tensile strain up 
to the peak strength in the long prismatic reinforced specimen is more than two times that of the dog-bone shaped specimen. The smaller strain in the dog-bone shaped specimen possibly resulted from the fact that smaller specimens are more sensitive to defects such as non-uniformly distributed fibers and coarse aggregates. Furthermore, without continuous reinforcement, crack extension is more likely to become unstable during stressing.

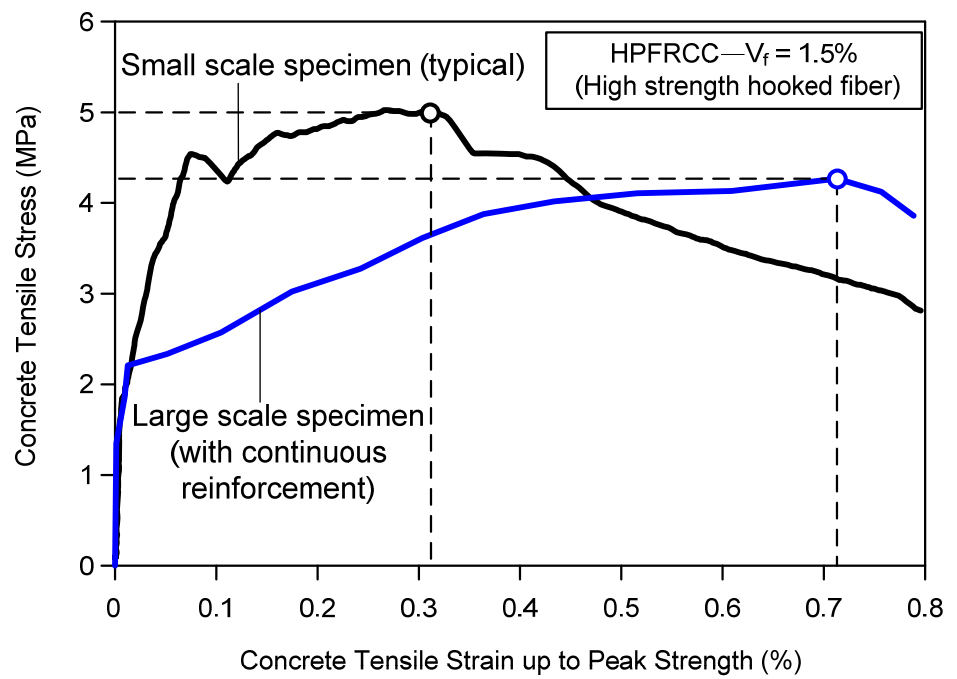

Figure 8: Comparison of stress-strain responses between dog-bone and long prismatic reinforced specimens using HF-SHFRC mixture.

\section{Conclusion}

Based on the experimental studies and analyses, the following conclusions can be drawn:

Only the slump flow test was used in this study to observe workability. Flow diameters about $600 \mathrm{~mm}$ were achieved in most cases. While the flowability of HF-SHFRC was not as high as the conventional SCC without fibers, it was deemed sufficient for practical implementation, with slight vibration when needed. In addition, larger scale specimens have been cast by using these mixtures described here, and the flowability was quite satisfactory with no segregation observed.

Segregation of fibers was greatly reduced by using viscosity modifying agent, VMA. The mixtures became viscous enough to bring fibers to the edge of the slump base plate during slump flow test. No segregation was observed either in this experimental program or other large scale specimens which were carried out by other researchers using the same mixtures.

Specimens made from the hardened composites were tested for compressive strength and tensile stress-strain response. The HF-SHFRC developed have 
compressive strengths ranging from about 35 to $66 \mathrm{MPa}$ and a tensile strengths ranging from 3.6 to 6.6 MPa obtained from direct tensile tests (dog-bone shaped specimens). They also showed strain-hardening response in tension, accompanied by multiple cracking. The peak strain capacity after first cracking in tension ranged from $0.25 \%$ to $0.45 \%$.

The peak tensile strength obtained from dog-bone shaped specimens was generally higher than that of long prismatic reinforced specimens. The tensile strain at the onset of damage localization in the long prismatic reinforced specimens was about twice that observed in the dog-bone shaped specimens where no reinforcement was used. The presence of continuous reinforcement leads to a significantly better crack development as well as a significant increase in energy absorption capacity.

\section{References}

[1] Naaman, A. E., "High-performance fiber reinforced cement composites," Concrete Structures for the Future, IABSE Symposium, Zurich, pp.371-376, 1987.

[2] Naaman, A. E., "Strain Hardening and Deflection Hardening Fiber Reinforced Cement Composites," High Performance Fiber Reinforced Cement Composites 4, Proceedings of the Fourth International RILEM Workshop, pp. 95-113, 2003.

[3] Liao, W.-C.; Chao, S.-H.; Park, S.-Y., and Naaman, A.E., "SelfConsolidating High Performance Fiber Reinforced Concrete (SCHPFRC) Preliminary Investigation," Technical Report No. UMCEE 06-02, University of Michigan, Ann Arbor, MI, pp. 68, 2006.

[4] Liao W.-C., Chao, S.-H., and Naaman, A. E. "Experience with SelfConsolidating High Performance Fiber Reinforced Mortar and Concrete," ACI Journal, Special Publication No. 247 "Fiber Reinforced SelfConsolidating Concrete - Research and Applications", pp. 79-94, 2010.

[5] Bui, V. K., Geiker, M. R., Shah, S. P., "Rheology of Fiber-Reinforced Cementitious Materials," RILEM PRO30 High Performance Fibre Reinforced Composites HPFRCC4, pp. 221-232, 2003.

[6] Chao, S.-H., Liao, W.-C. and Naaman, A. E. "Large Scale Tensile Tests of High Performance Fiber Reinforced Cement Composites.” RILEM PRO53 High Performance Fibre Reinforced Composites HPFRCC5, pp. 77-86, 2007.

[7] Chao, S.-H., Naaman, A. E. and Parra-Montesinos, G. J., 'Bond Behavior of Strands Embedded in Fiber Reinforced Cementitious Composites', PCI Journal, 51 (6), Precast/Prestressed Concrete Institute, pp. 56-71, 2006. 